\title{
Interrelationship of Millennial Generation Leadership Style Indicators at PLN Central Java \& DIY Distribution Main Unit Using Interpretive Structural Modeling (ISM) Approach
}

\section{Hubungan Antar Indikator Gaya Kepemimpinan Generasi Milenial di PLN Unit Induk Distribusi Jateng \& DIY Menggunakan Pendekatan Interpretive Structural Modeling (ISM)}

\author{
Muhdam Azhar ${ }^{1 *}$, Mahfudz ${ }^{1}$ \\ ${ }^{1}$ Program Studi Magister Manajemen, Universitas Diponegoro \\ Jl. Prof Sudarto S No.1, Pleburan, Semarang, Kode pos: 50241 \\ email : muhdam.azhar@gmail.com \\ doi: https://doi.org/10.31315/opsi.v14i2.6303
}

Received: $3^{\text {rd }}$ December 2021; Revised: $5^{\text {th }}$ December 2021; Accepted: $6^{\text {th }}$ December 2021;

Available online: 21 ${ }^{\text {st }}$ December 2021; Published regularly: December 2021

\begin{abstract}
Manager at PT. PLN Persero has an important role in balancing internal relations with employees and external parties such as stakeholders. PT. PLN (Persero) Distribution Central Java and Yogyakarta D.I consists of a Unit Pelaksana Pelayanan Pelanggan (UP3) and Unit Layanan Pelanggan (ULP), ULP is directly related to the community and stakeholders. ULP Managers consists of Millennial Generation is $87 \%$ and Generation X 13\%. The generation gap between Generation $X$ and Generation $Y$ (millennials) caused by the 7 years vacuum of recruitment, it causes of communication problems and Generation Y rapid adaptation to become young managers. Indicators identification are needed related to Generation Y's leadership style so that young managers are better prepared. Identification of the relationship between indicators is carried out using the Interpretive Structural Modeling (ISM) method and then classifying indicators using the Multiplication Applied to a Classification (MICMAC) method. There are 7 indicators obtained from ISM: M1 (Communication Method), M2 (Media Communication), M3 (Managing Team Involvement), M4 (Resolving Internal Conflicts), M5 (Risk Management), M6 (Responding to Change), M7 (Managing Stakeholder). MICMAC analysis results are M7 in the Dependent Indicators Cluster, the other indicators from M1, M2, M3, M4, M5, M6 are in the Linkage Indicators Cluster.
\end{abstract}

Keywords: ISM, MICMAC, leadership, millennial generation

\begin{abstract}
ABSTRAK
Manajer di PT. PLN Persero memiliki peran penting dalam menyeimbangkan pengelolaan hubungan internal dengan karyawan maupun dengan pihak eksternal seperti pemangku kepentingan. PT. PLN (Persero) Distribusi Jawa Tengah dan D.I Yogyakarta terdiri dari Unit Pelaksana Pelayanan Pelanggan (UP3) dan Unit Layanan Pelanggan (ULP) dimana ULP inilah yang berkaitan langsung dengan masyarakat dan pemangku kepentingan. Komposisi jumlah Manajer ULP Generasi Milenial 87\% dan Generasi X 13\%. Adanya gap generasi antara Generasi $X$ dan Generasi $Y$ (milenial) disebabkan oleh vakumnya rekrutmen hingga 7 tahun menyebabkan kendala komunikasi dan adaptasi Generasi Y yang cepat untuk menjadi manajer muda. Diperlukan identifikasi indikator-indikator apa saja yang terkait dengan gaya kepemimpinan Generasi Y agar manajer muda lebih siap dan perusahaan dapat lebih berkembang. Identifikasi hubungan antar indikator dilakukan dengan metode Interpretive Structural Modeling (ISM) dan kemudian mengklasifikasikan indikator-indikator tersebut menggunakan metode Multiplication Applied to a Classification (MICMAC). Terdapat 7 indikator yang didapatkan dari ISM, diantaranya: M1 (Cara berkomunikasi), M2 (Media Komunikasi), M3 (Mengatur Keterlibatan Tim), M4 (Mengatasi Konflik Internal), M5 (Manajemen Risiko), M6 (Merespon Perubahan), M7 (Mengelola Pemangku Kepentingan). Untuk hasil analisis MICMAC, Indikator M7 berada pada Cluster
\end{abstract}


Dependent Indicators, sedangkan indikator lainnya dari M1, M2, M3, M4, M5, M6 berada pada Cluster Linkage Indicators.

Kata Kunci: ISM, MICMAC, kepimpinan, generasi milenial

\section{PENDAHULUAN}

PT PLN (Persero) merupakan Badan Usaha Milik Negara yang bergerak di sektor vital dengan memberikan pelayanan distribusi tenaga listrik kepada masyarakat. Pekerjaan yang banyak berkaitan dengan lingkup eksternal menjadikan manajer memiliki peran penting sebagai wakil dari unitnya. Kemampuan berkomunikasi pengelola dengan pemangku kepentingan eksternal, seperti bupati atau walikota, ketua DPRD, pegiat ormas, dan lainnya dinilai menjadi salah satu indikator keberhasilan kinerja.

Tanggapan pemimpin terhadap persepsi pemangku kepentingan dan keahlian teknis serta kemampuan sosial untuk memimpin wilayah kerjanya adalah hal yang perlu diperhatikan (Tran et al., 2016). Pemahaman pemimpin terkait perbedaan generasi dalam organisasi diperlukan untuk mendapatkan kepercayaan dari tim mengenai pengambilan keputusan (Shrivastava \& Savolainen, 2017).

PT. PLN (Persero) Distribusi Jawa Tengah dan D.I Yogyakarta memiliki 13 Unit Pelaksana Pelayanan Pelanggan (UP3) dan di bawahnya terdapat 79 Unit Layanan Pelanggan (ULP) yang melayani masyarakat secara langsung. Karyawan PT. PLN (Persero) Distribusi Jawa Tengah dan D.I Yogyakarta berjumlah 1.795 orang yang terdiri dari dua generasi yaitu Generasi X dan Generasi Y (Generasi Milenial). Menurut (Shrivastava \& Savolainen, 2017), Generasi X lahir pada tahun 1965-1980 sedangkan Generasi Y (Milenial) lahir pada tahun 1981-2001. Data pegawai disajikan pada Tabel 1.

Tabel 1. Komposisi Pegawai PT PLN Unit Induk Distribusi Jateng \& DIY

\begin{tabular}{lccc}
\hline \multicolumn{1}{c}{ Generasi } & \multicolumn{2}{c}{ Gender } & Jumlah \\
& Perempuan & Pria & \\
\hline X & 141 & 289 & 430 \\
Y / Millennial & 406 & 959 & 1365 \\
Total & $\mathbf{5 4 7}$ & $\mathbf{1 2 4 8}$ & $\mathbf{1 7 9 5}$ \\
\hline
\end{tabular}

Dari keseluruhan data pegawai yang terlihat pada Tabel 1. terdapat 79 komposisi Manajer ULP pada Tabel 2.

Berdasarkan Tabel 2. Manajer ULP dari Milenial mencapai $87 \%$ dan Generasi X sebesar $13 \%$. Hal ini terjadi karena proses rekrutmen yang vakum dari tahun 1996 - 2003, sehingga terjadi gap generasi yang menyebabkan pegawai muda harus siap menjadi manajer di tingkat ULP. Anggota yang harus dipimpin mayoritas manajer adalah dari Generasi Y atau Generasi Milenial, proporsi ini akan terus bertambah seiring dengan semakin banyaknya karyawan Generasi X yang akan pensiun.

Tabel 2. Komposisi Manajer ULP PT PLN Unit Induk Distribusi Jateng \& DIY

\begin{tabular}{lccc}
\multicolumn{4}{c}{ Induk Distribusi Jateng \& DIY } \\
\hline \multicolumn{1}{c}{ Generasi } & Gender & Jumlah \\
& Perempuan & Pria & \\
\hline $\mathrm{X}$ & 3 & 7 & 10 \\
Y / Millennial & 11 & 58 & 69 \\
Total & $\mathbf{1 4}$ & $\mathbf{6 5}$ & $\mathbf{7 9}$ \\
\hline
\end{tabular}

Hubungan antara pemimpin dan bawahan berubah dari waktu ke waktu (Caulfield \& Senger, 2017). Bupati atau Walikota dan pimpinan daerah lainnya yang tergabung dalam forum komunikasi kepala daerah, kecamatan, atau bahkan kepala desa yang merupakan pihak eksternal juga berasal dari berbagai generasi. Komunikasi dan pengembangan hubungan interpersonal dengan para pemangku kepentingan ini juga menjadi tolok ukur keberhasilan manajer dalam menciptakan keunggulan kompetitif (Wijono, 2006).

Penelitian yang dilakukan oleh Akmalaputri et al., (2018) di PT PLN (Persero) Area Pengatur Beban Jateng dan DIY menyimpulkan bahwa Generasi Y (Generasi Milenial) memiliki cara unik selain Coaching, Mentoring, dan Counseling (CMC) yaitu dengan mengaktifkan aplikasi WhatsApp Group (WAG) dan berkumpul bersama sebagai langkah untuk mendistribusikan informasi sasaran dan regenerasi peran. Pemimpin generasi X lebih suka menggunakan $\mathrm{CMC}$, Code 
of Conduct (COC), dan Person in Charge (PIC) untuk pola regenerasi.

Lain halnya dengan penelitian yang dilakukan oleh (Tran et al., 2016), penelitian yang dilakukan di BUMN Vietnam menjelaskan bahwa para pemimpin perlu mengetahui perbedaan generasi yang dipimpinnya untuk mendapatkan kepercayaan dari tim, terutama dalam pengambilan keputusan. Perbedaan Generasi ini dianggap sebagai tantangan atau peluang bagi para pemimpin yang menginginkan dukungan kolegial, terutama dari para pemangku kepentingan.

Penelitian Rony (2019) membahas kesamaan karakteristik dan karakter Generasi Y dengan kepemimpinan inovatif. Keduanya memiliki karakteristik penantang, visioner, dan senang berinovasi. Persamaan yang begitu kuat membuat GenY memiliki bekal untuk menjadi pemimpin yang inovatif di abad ke- 21 .

Studi mengenai model hubungan gaya kepemimpinan masih belum banyak dilakukan. Rafiq et al. (2021) membahas mengenai keberhasilan organisasi energi yang tidak lepas dari peran praktik manajemen. Pengumpulan data dilakukan dengan mewawancarai manajer tingkat atas dan menengah yang bekerja di sektor energi terbarukan di negara berkembang. Metodologi penelitiannya adalah kualitatif dengan pemikiran logis dan penyelesaian masalah kompleks menggunakan Interpretive Structural Modeling (ISM).

Ma et al. (2019) menganalisis faktor-faktor yang mempengaruhi adopsi penerapan Building Information Modeling (BIM) pada Perusahaan Konstruksi di China. Faktor-faktor tersebut diidentifikasi dan didapatkan 21 faktor melalui literature review. Kemudian membangun struktur hierarki menggunakan teknik Interpretive Structural Modeling (ISM) dan mengklasifikasikan faktor-faktor tersebut menggunakan metode Multiplication Applied to a Classification (MICMAC).

\section{METODE}

Penelitian ini bertujuan untuk mengetahui dan menganalisis hubungan indikator-indikator yang mempengaruhi gaya kepemimpinan generasi milenial di ULP menurut sudut pandang manajer, bawahan, dengan kondisi dominasi karyawan milenial, baik pemimpin maupun anggota di masa depan.

\subsection{Instrumen Pengumpulan Data}

Terdapat dua jenis sumber data yang digunakan pada penelitian ini. Sumber data primer seperti literature review terkait studi gaya kepemimpian milenial beserta identifikasi indikator dapat dilihat pada Tabel 3. Teknik penyelesaian masalah serta observasi lapangan dilakukan dengan wawancara. Wawancara dengan expert dilakukan menggunakan aplikasi pertemuan berbasis online, seperti Zoom, WhatsApp, Skype, dan lain-lain. Peneliti mewawancarai expert dengan mengajukan kuesioner terkait hubungan indikator dan menggali informasi lebih lanjut mengenai indikator yang mungkin perlu ditambahkan atau dihilangkan. Sedangkan data sekunder berupa dokumen perusahaan digunakan sebagai pelengkap data primer.

Expert yang terlibat adalah 5 orang narasumber mewakili Manajer ULP. Kriteria expert yang ditentukan peneliti: Manajer ULP yang memiliki kinerja individu dan unit yang baik, dibuktikan dengan hasil penilaian kinerja yang dikeluarkan oleh PT PLN (Persero) Distribusi Jawa Tengah dan D.I Yogyakarta, dan minimal 2 (dua) tahun menduduki posisi top supervisor.

\subsection{Teknik Pengolahan Data}

Interpretive Structural Modeling (ISM) adalah metode yang digunakan untuk menunjukkan hubungan langsung atau tidak langsung dari beberapa variabel dalam suatu sistem yang kompleks. Konsep teori graf digunakan untuk membantu menunjukkan keterkaitan dan ketergantungan antara variabelvariabel tersebut, yang dituangkan dalam bentuk digraf dan matriks (Kota et al., 2021). Tahapan pengolahan data ditunjukkan pada Gambar 1.

Ide dasar dari ISM adalah menggunakan pendapat dan pengetahuan para ahli untuk menguraikan sistem yang kompleks menjadi beberapa sub-sistem dan mengatur model struktural bertingkat. ISM membantu mengidentifikasi arah yang kompleks dan hubungan antar elemen dalam sistem (Sage, 1977).

\subsubsection{Literature Review}

Tahapan awal dari ISM-MICMAC adalah mengidentifikasi indikator-indikator terkait gaya kepemimpinan generasi milenial dengan melakukan literature review dan diskusi dengan expert. Indikator yang didapatkan dapat dilihat pada Tabel 3. 


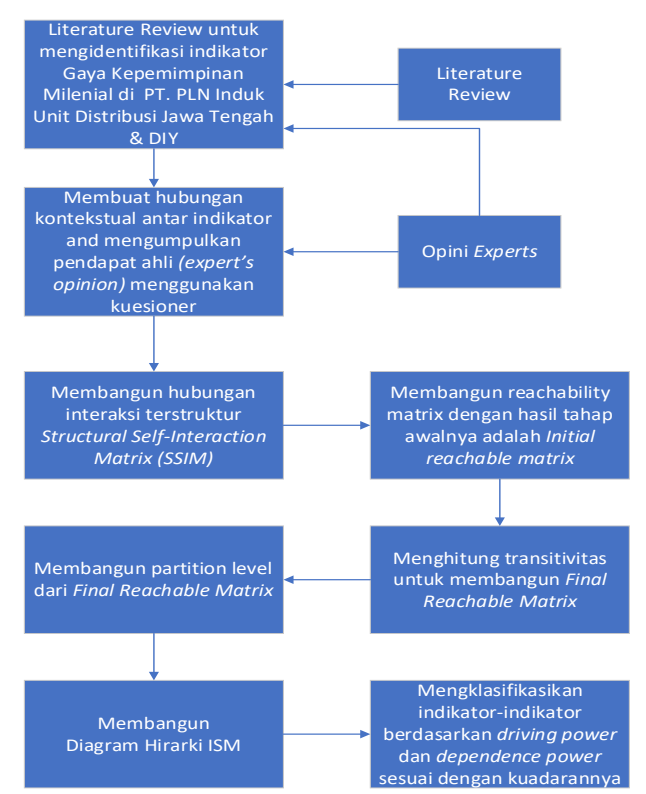

Gambar 1. Tahapan ISM-MICMAC

Tabel 3. Indikator Gaya Kepemimpinan Milenial PT PLN Unit Induk Distribusi Jateng \& DIY

\begin{tabular}{|c|c|c|c|}
\hline No. & Indikator & Kode & Sumber \\
\hline 1 & $\begin{array}{l}\text { Cara } \\
\text { berkomunikasi }\end{array}$ & M1 & (Rony, 2019) \\
\hline 2 & $\begin{array}{l}\text { Media } \\
\text { Komunikasi }\end{array}$ & M2 & $\begin{array}{l}\text { (Akmalaputri et } \\
\text { al., 2018; Ma et } \\
\text { al., 2019; Rony, } \\
\text { 2019) }\end{array}$ \\
\hline 3 & $\begin{array}{l}\text { Mengatur } \\
\text { Keterlibatan } \\
\text { Tim }\end{array}$ & M3 & $\begin{array}{l}\text { (Akmalaputri et } \\
\text { al., 2018; Ma et } \\
\text { al., 2019; Rony, } \\
\text { 2019) }\end{array}$ \\
\hline 4 & $\begin{array}{l}\text { Mengatasi } \\
\text { Konflik } \\
\text { Internal }\end{array}$ & M4 & $\begin{array}{l}\text { (Akmalaputri et } \\
\text { al., 2018; Rafiq } \\
\text { et al., 2021) }\end{array}$ \\
\hline 5 & $\begin{array}{l}\text { Manajemen } \\
\text { Risiko }\end{array}$ & M5 & $\begin{array}{l}\text { (Tran et al., } \\
\text { 2016) }\end{array}$ \\
\hline 6 & $\begin{array}{l}\text { Merespon } \\
\text { Perubahan }\end{array}$ & M6 & $\begin{array}{l}\text { (Akmalaputri et } \\
\text { al., 2018; Rafiq } \\
\text { et al., 2021) }\end{array}$ \\
\hline 7 & $\begin{array}{l}\text { Mengelola } \\
\text { Pemangku } \\
\text { Kepentingan }\end{array}$ & M7 & $\begin{array}{l}\text { (Tran et al., } \\
\text { 2016) } \\
\text { Observasi }\end{array}$ \\
\hline
\end{tabular}

\subsubsection{Membuat Hubungan Kontekstual dengan Kuesioner}

Kuesioner dibuat berdasarkan indikatorindikator yang dikembangkan pada elemen dan hubungan kontekstual perbandingan antar indikator. Kuesioner diberikan kepada para ahli untuk menguji hubungan antar variabel. Pada penelitian ini, kuesioner disebar menggunakan google form.

\subsubsection{SSIM Matrix}

Menurut (Raeesi et al., 2016), matriks SSIM digunakan untuk menginvestigasi semua hubungan antara dua indikator $\mathrm{i}$ dan $\mathrm{j}$ dan arah hubungan yang terkait.

Empat simbol yang digunakan adalah V, A, $\mathrm{X}$ dan $\mathrm{O}$. Penjelasan masing-masing simbol adalah sebagai berikut:

$\mathrm{V}$ - Indikator i mempengaruhi indikator $\mathrm{j}$;

A - Indikator $\mathrm{j}$ mempengaruhi indikator $\mathrm{i}$;

$X$ - Indikator $\mathrm{i}$ dan $\mathrm{j}$ saling mempengaruhi; dan $\mathrm{O}$ - Indikator i dan $\mathrm{j}$ tidak berhubungan.

\subsubsection{Initial Reachable Matrix (IRM)}

Indikator - indikator pada SSIM ditransformasikan menjadi IRM, simbol V, A, X dan $\mathrm{O}$ diganti dengan nilai 0 atau 1 sesuai dengan Rumus (1).

$$
(i, j)=\left\{\begin{array}{cc}
V, & (i, j)=1,(j, i)=0 \\
A, & (i, j)=0,(j, i)=1 \\
X, & (i, j)=1,(j, i)=1 \\
O, & (i, j)=0,(j, i)=0
\end{array}\right.
$$

\subsubsection{Final Reachable Matrix (FRM) \\ a. Transitivitas}

Untuk membangun FRM, perlu mempertimbangkan efek transitivitas di IRM. Dimisalkan tiga variabel X, Y, Z, jika variabel X berhubungan dengan variabel $Y$ dan variabel $Y$ berhubungan dengan variabel $Z$, maka variabel $X$ juga harus terkait dengan variabel $Z$ (Primadasa et al., 2019).

\section{b. Matriks akhir}

Matriks akhir berasal dari hasil transitivitas yang kemudian dapat dihitung driving power pada sumbu vertikal dan dependent power pada sumbu horizontal.

\subsubsection{Partition Level}

Pada tahap ini menggunakan acuan dari hasil akhir FRM untuk memperoleh reachability dan antecedent set (Warfield, 1974). Nantinya akan dilakukan iterasi terkait penentuan level dari indikator-indikator yang telah diketahui hubungannya.

\subsubsection{Membuat Diagram Hirarki ISM}

Diagram hirarki dibuat sesuai dengan level indikator yang didapatkan dari hasil partition level. 


\subsubsection{Analisis MICMAC}

Teknik MICMAC digunakan untuk mengklasifikasikan indikator-indikator tersebut berdasarkan driving dan dependence power (Ma et al., 2019) berbentuk diagram kartesius.

\section{HASIL DAN PEMBAHASAN}

Berdasarkan studi literatur pada Tabel 3, para expert memberikan penilaian hubungan kontekstual melalui kuesioner dan hasilnya dibuat berbentuk matriks SSIM pada Tabel 4.

Tabel 4. Matriks SSIM

\begin{tabular}{ccccccc}
\hline Kode & M7 & M6 & M5 & M4 & M3 & M2 \\
\hline M1 & V & V & A & A & V & X \\
M2 & A & A & V & A & X & \\
M3 & V & A & A & X & & \\
M4 & O & X & X & & & \\
M5 & V & A & & & & \\
M6 & X & & & & & \\
M7 & & & & & & \\
\hline
\end{tabular}

Kemudian mengubah simbol pada matriks SSIM menjadi Initial Reachable Matrix (IRM), transformasinya dapat dilihat pada Tabel 5.

Tabel 5. Initial Reachable Matrix

\begin{tabular}{lccccccc}
\hline Kode & M1 & M2 & M3 & M4 & M5 & M6 & M7 \\
\hline M1 & 0 & 1 & 1 & 0 & 0 & 1 & 1 \\
M2 & 1 & 0 & 1 & 0 & 1 & 0 & 0 \\
M3 & 0 & 1 & 0 & 1 & 0 & 0 & 1 \\
M4 & 1 & 1 & 1 & 0 & 1 & 1 & 0 \\
M5 & 1 & 0 & 1 & 1 & 0 & 0 & 1 \\
M6 & 0 & 1 & 1 & 1 & 1 & 0 & 1 \\
M7 & 0 & 1 & 0 & 0 & 0 & 1 & 0 \\
\hline
\end{tabular}

Tahapan selanjutnya mengubah IRM ke FRM dengan melakukan transitivitas indikator. Sebagai contoh: $\mathrm{M} 1=>\mathrm{M} 2=>\mathrm{M} 5, \quad \mathrm{M} 1$ mempengaruhi M2, dan M2 mempengaruhi M5, sehingga M1 juga mempengaruhi M5. Jadi nilai 0 pada M5 diganti nilai 1. Perubahan keseluruhan dapat dilihat pada Tabel 6.
Tabel 6. Final Reachable Matrix

\begin{tabular}{lcccccccc}
\hline $\begin{array}{l}\text { Ko- } \\
\text { de }\end{array}$ & M1 & M2 & M3 & M4 & M5 & M6 & M7 & Dri. \\
\hline M1 & 0 & 1 & 1 & 1 & 1 & 1 & 1 & $\mathbf{6}$ \\
M2 & 1 & 0 & 1 & 1 & 1 & 0 & 1 & $\mathbf{5}$ \\
M3 & 1 & 1 & 0 & 1 & 1 & 1 & 1 & $\mathbf{6}$ \\
M4 & 1 & 1 & 1 & 0 & 1 & 1 & 1 & $\mathbf{6}$ \\
M5 & 1 & 1 & 1 & 1 & 0 & 1 & 1 & $\mathbf{6}$ \\
M6 & 1 & 1 & 1 & 1 & 1 & 0 & 1 & $\mathbf{6}$ \\
M7 & 1 & 1 & 0 & 0 & 0 & 1 & 0 & $\mathbf{3}$ \\
Dep. & $\mathbf{6}$ & $\mathbf{6}$ & $\mathbf{5}$ & $\mathbf{5}$ & $\mathbf{5}$ & $\mathbf{5}$ & $\mathbf{6}$ & \\
\hline
\end{tabular}

Setelah membangun FRM, maka langkah selanjutnya adalah menentukan level indikator (partition level) yang nantinya untuk pedoman pembuatan diagram hirarki.

Untuk memahami hubungan hirarki dari indikator-indikator yang mempengaruhi, himpunan Reachability Set disimbolkan R set dengan melihat nilai indikator secara horizontal dan himpunan Antesedent Set disimbolkan A Set dari nilai indikator yang dilihat secara vertikal. Kemudian indikator yang beririsan dicantumkan pada Intersection Set disimbolkan dengan I Set yang menentukan pelevelan. Keseluruhan iterasi dari partition level disajikan pada Tabel 7.

Tabel 7. Partition Level

\begin{tabular}{lcccc}
\hline $\begin{array}{l}\text { Ko- } \\
\text { de }\end{array}$ & R set & A Set & I Set & Level \\
\hline M1 & $2,3,4,5,6,7$ & $2,3,4,5,6,7$ & $2,3,4,5,6,7$ & 1 \\
M2 & $1,3,4,5,7$ & $1,3,4,5,6,7$ & $1,3,4,5,7$ & 2 \\
M3 & $1,2,4,5,6,7$ & $1,2,4,5,6$ & $1,2,4,5,6$ & 2 \\
M4 & $1,2,3,5,6,7$ & $1,2,3,5,6$ & $1,2,3,5,6$ & 2 \\
M5 & $1,2,3,4,6,7$ & $1,2,3,4,6$ & $1,2,3,4,6$ & 2 \\
M6 & $1,2,3,4,5,7$ & $1,3,4,5,7$ & $1,3,4,5,7$ & 2 \\
M7 & $1,2,6$ & $1,2,3,4,5,6$ & $1,2,6$ & 1 \\
\hline
\end{tabular}

Berdasarkan hasil partition level pada Tabel 7. didapatkan 2 level dari hasil iterasi. Hal tersebut dapat terjadi karena berdasarkan penilaian experts, antar indikator berkaitan erat satu sama lain. Sehingga, keberhasilan indikator M1 (Cara berkomunikasi) dan M7 (Mengelola Pemangku Kepentingan) sangat bergantung dengan indikator M2, M3, M4, M5, dan M6. Agar struktur hirarki dari indikator terlihat jelas, maka diperlukan pembuatan diagram yang disajikan pada Gambar 2. 


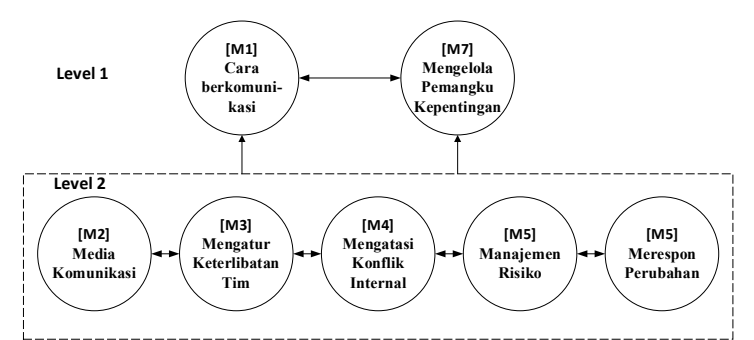

Gambar 2. Diagram Hirarki ISM

Setelah pembuatan diagram, langkah selanjutnya adalah melakukan analisis dengan metode MICMAC. Pada tahap ini melakukan clustering indikator menggunakan diagram kartesius berdasarkan nilai driving power dan dependence power yang telah dihitung pada Tabel 6.

Klasterisasi pada MICMAC Analysis (Primadasa et al., 2019) dibagi sebagai berikut:

- Cluster 1: Autonomous Indicators: memiliki ketergantungan (dependence) yang lebih kecil dan daya penggerak (driving) yang juga kecil, cenderung tidak terkait dengan indikator lain.

- Cluster 2: Dependent Indicators: Indikator ini memiliki ketergantungan yang kuat tetapi daya penggeraknya rendah.

- Cluster 3: Linkage Indicators: Indikatorindikator ini memiliki ketergantungan tinggi dan daya penggeraknya juga tinggi.

- Cluster 4: Independent Indicators: indikator yang memiliki ketergantungan lemah tetapi daya penggeraknya tinggi.

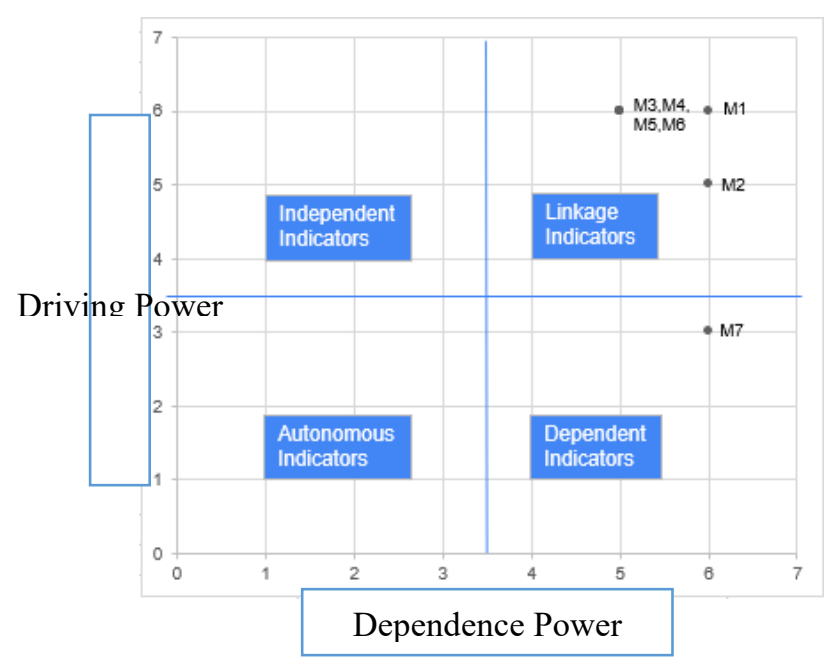

Gambar 3. Klasifikasi Indikator - MICMAC

Berdasarkan Gambar 3., terlihat indikator M7 (Mengelola Pemangku Kepentingan) berada di Cluster 2: Dependent Indicators yang berarti ketergantungannya dengan indikator lain tinggi dan bersifat sensitif apabila terdapat perubahan dari indikator lainnya. Kemudian indikator lainnya: M1, M2, M3, M4, M5, M6 berada pada cluster yang sama, yaitu Cluster 3: Linkage Indicators yang artinya, indikator-indikator tersebut memiliki hubungan kuat terutama dengan indikator dependen. Maka manajer milenial disarankan agar lebih fokus pada indikator-indikator tersebut untuk kelangsungan dan peningkatan kinerja perusahaan.

\section{KESIMPULAN}

Indikator yang didapatkan pada penelitian ini adalah 7 indikator yang terdiri dari: M1 (Cara berkomunikasi), M2 (Media Komunikasi), M3 (Mengatur Keterlibatan Tim), M4 (Mengatasi Konflik Internal), M5 (Manajemen Risiko), M6 (Merespon Perubahan), M7 (Mengelola Pemangku Kepentingan).

Hasil ISM dari indikator-indikator yang didapatkan terdapat 2 level dimana level 1 terdiri dari indikator M1 dan M7, kemudian level 2 terdiri dari indikator M2, M3, M4, M5, M6.

Klasifikasi indikator menggunakan MICMAC menunjukkan bahwa indikatorindikator hanya terpecah menjadi 2 cluster, diantaranya: Indikator M7 berada pada Cluster 2: Dependent Indicators, sedangkan indikator lainnya dari M1, M2, M3, M4, M5, M6 berada pada Cluster 3: Linkage Indicators.

Untuk penelitian selanjutnya diharapkan dapat menambah indikator-indikator yang terkait dan memperluas objek penelitian.

\section{DAFTAR PUSTAKA}

Akmalaputri, A. G., Yuniawan, A., \& Djastuti, I. (2018). Gen Y Leader: Qualitative Phenomenology Leadership Studies In Pln Apd Jateng \& Diy. Jurnal Bisnis Strategi, 26(1), 62. https://doi.org/10.14710/jbs.26.1.62-75

Caulfield, J. L., \& Senger, A. (2017). Perception is Reality: Change Leadership and Work Engagement Organizational Change And Work Engagement: The Mediating Effect Of Leadership. Leadership \& Organization Development Journal, 38(7), $1-41$.

Kota, S., Mishra, R. P., Krishna Jasti, N. V., \& Kale, S. (2021). Sustainable Production 
System Critical Success Factors: An Interpretive Structural Modelling approach. Procedia CIRP, 98, 324-329. https://doi.org/10.1016/j.procir.2021.01.1 11

Ma, G., Jia, J., Ding, J., Shang, S., \& Jiang, S. (2019). Interpretive Structural Model Based Factor Analysis of BIM Adoption in Chinese Construction Organizations. https://doi.org/10.3390/su11071982

Primadasa, R., Sokhibi, A., \& Tauhida, D. (2019). Interrelationship of Green Supply Chain Management (GSCM) Performance Indicators for Palm Oil Industry in Indonesia. IOP Conference Series: Materials Science and Engineering, 598(1). https://doi.org/10.1088/1757899X/598/1/012034

Raeesi, R., Dastranj, M., Mohammadi, S., \& Rasouli, E. (2016). Understanding the Interactions among the Barriers to Entrepreneurship Using Interpretive Structural Modeling Understanding the Interactions among the Barriers to Entrepreneurship Using Interpretive Structural Modeling. June 2013. https://doi.org/10.5539/ijbm.v8n13p56

Rafiq, M., Naz, S., Martins, M., Mata, N., \& Mata, P. N. (2021). A Study on Emerging Management Practices of Renewable Energy Companies after the Outbreak of Covid-19: Using an Interpretive Structural Modeling ( ISM) Approach.
Rony, Z. T. (2019). Generation Y Challenges in Becoming Innovative Leaders at Organization in the 21st Century. November. https://doi.org/10.35940/ijrte.B1164.0982 S919

Sage, A. P. (1977). Interpretive Structural Modeling: Methodology for Large-Scale Systems Sage, A.P. 1977 New York: McGraw-Hill. 1977.

Shrivastava, P., \& Savolainen, T. (2017). Trust, Leadership Style and Generational Differences at Work-A Qualitative Study of a Three-Generation Workforce from Two Countries. Trust, Leadership Style and Generational Differences at Work ... $N J B, 66(4)$.

Tran, D. M., Fallon, W., \& Vickers, M. H. (2016). Leadership in Vietnamese state owned enterprises (SOEs). Asia-Pacific Journal of Business Administration, 8(1), 21-36. https://doi.org/10.1108/APJBA10-2014-0116

Warfield, J. N. (1974). Developing Subsystem Matrices in Structural Modeling. IEEE Transactions on Systems, Man and Cybernetics, SMC-4(1), 74-80. https://doi.org/10.1109/TSMC.1974.5408 523

Wijono, S. (2006). Pengaruh Kepribadian Type A dan Peran Terhadap Stres Kerja Manajer Madya. Jurnal INSAN, 8(3), 188-197. 